Georges Braque, who had been evolving forms of cubism since 1908, and others, who had been aping them since 1910, for failing to represent objects as they are, as he argued they should do.

In his final chapter, "Monet's brain", Zeki ties himself in knots. Claude Monet clearly does not fulfil Zeki's dictum that art should "represent the constant, lasting, essential and enduring features of objects". $\mathrm{He}$ is baffled by Monet's ability to represent not the constant colourings of the world but appearances under changing light conditions. Such features, Zeki claims, are visible only to brain-damaged "dyschromatopsics" (people suffering from a disorder of colour vision).

It has often been claimed, says Zeki, that Monet "painted with his eye, but, Great God, what an eye". But he wants to show that even for Monet "the higher cerebral centres played a very critical role in his work" - a truism, surely - and, also, "that his work was far from being an attempt to capture the fugitive moments". How far, exactly?

Monet's 30 canvases of the west front of Rouen cathedral under diverse light conditions, painted in 1892-94, might suggest, at a glance, says Zeki, that Monet could have been dyschromatopsic. "The suggestion is insulting if not laughable", he continues. $\mathrm{He}$ then identifies the areas of the visual cortex that would have been activated as Monet painted. "All this can be surmised from what happens in the brain of a normal subject when he $[$ sic $]$ views a coloured scene."

Zeki claims Monet "was, in fact, using the knowledge in his brain to deliberately paint something that departed from what he was actually seeing".

But Monet had been a professional and most prolific painter for more than 30 years when he painted the cathedral series. He had spent hours of each day studying and attempting to depict just those qualities of changing light that most of us, concerned with our own affairs, are indifferent to but which, nevertheless, are not invisible to us. Otherwise, we would not enjoy Monet's paintings. Having seen his images, we can return to the world and see it through his eyes. For Monet, his professional skill was also his curse. Looking at his wife on her death bed, he wrote: "I caught myself watching her tragic forehead, almost mechanically observing the sequence of changing colours which death was imposing on her rigid face. Blue, yellow, grey and so on."

Although Zeki tells us much about the functioning of the visual cortex, his observations on paintings are not illuminating. But do read A Vision of the Brain. It is truly impressive.

John Nash is in the Department of Art History and Theory, University of Essex, Colchester CO4 3SQ, UK.

\section{Science's stall in the global market-place}

\section{On the Edge: Living with Global Capitalism \\ edited by Will Hutton \\ and Anthony Giddens \\ Jonathan Cape: 2000. 241 pp. 28.99 (pbk) \\ Norman Myers}

Every day a whopping $\$ 1.5$ trillion shuttles back and forth through the stock exchanges of the world. That's quite a slice of the $\$ 32$ trillion global economy. Moreover, there is really only one big stock exchange, as Wall Street, the City of London and their counterparts in Frankfurt, Zurich, Tokyo and so on trade around the world's clock, intensifying the mobility of electronic capital. It funds economic activities with all manner of unknown repercussions. Which of my investments underpins over-logging in Cameroon, or sweatshop factories in Bangkok, or unsustainable farming in Mexico? Whatever my reservations about the process, I am globalizing as much as the rest of us. I am closely enough involved with billions of fellow members to shake financial hands with them or tread on their toes.

The same applies to the environment. If the Chinese, sitting on one-third of the planet's coal, burned their stocks to fuel development, that could pump as much carbon dioxide into everyone's atmosphere as would be avoided were Britain and Germany to get out of fossil fuels altogether. The planetary ecosystem is a seamless continuum, and the winds carry no passports.

These are some of the thoughts prompted by $O n$ The Edge, published this week, with its assessment of global and hence unitary capitalism. Of the 100 biggest economic entities in the world, only half are nation states, the rest being corporations. The world is no longer governed by governments alone and our daily lives - cultural perceptions, social mores, value systems, scientific endeavours - are increasingly determined by business leaders. Where are they leading us? If we want them to change direction, how can we make the message loud enough to be heard?

These issues are explored by 13 contributors, including economist Paul Volcker, investor George Soros, physicist and philosopher Vandana Shiva and journalist Polly Toynbee. They applaud the opportunities afforded by global-scale corporations. But they also alert us to the problems of profitsdriven business with its lack of social responsibility and its frequent indifference to externality costs, especially environmental costs, and other risks such as concentrated control of the media. They highlight the socio-economic apartheid of a winner-take-all system where many people will end up in exclusion.
The adverse environmental impacts have been widely documented, even though they attract little attention from international agencies. Notable examples include the inequitable use of tropical genetic resources for agriculture, and carbon dioxide emissions from the fossil fuels industry. According to the American analyst Paul Hawken, US businesses cause so many spillover costs - not just cancer from tobacco, pollution from cars and waste from manufacturing, but also the costs of community disruption - that they could cost society $\$ 3$ trillion per year, or five times their profits. Accountability, anyone?

Fortunately, a host of constraints on business practices are emerging, imposed as much by non-governmental organizations (NGOs) as by governments. In 1975 there were only 1,400 NGOs; today there are well over 30,000. These citizen activists, often globalized themselves, can deploy much muscle in the market-place: witness the 1995 campaign against Shell's plans to sink the Brent Spar oil platform. Similarly, NGOs have confronted RTZ and De Beers for supporting governments that ignore human rights.

Global capitalism has major implications for science, too. For one thing, there is a parallel globalization of the scientific community. Courtesy of the Internet and e-mail, scientists can engage in virtual conferencing with colleagues around the world. There has been a quantum advance in academic networking which transcends national boundaries and interests at the touch of a keyboard. This enables scientists to keep pace with the headlong expansion of global capitalism, and to induce scientific constraints on business activities. There will surely be many more GMO-style sagas.

For a second thing, science is increasingly pursued through the largesse of big business, notably in the form of pharmaceutical corporations with mega research budgets. A number of chemical companies control crop seeds and thus our food-chains through their biotechnologies.

Scientists are also involved through Britain's third largest pension fund, the Universities Superannuation Scheme, which,

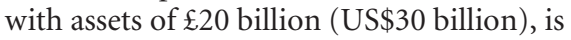
to challenge businesses over their environmental performance or unduly low wages.

All in all, this is an illuminating exploration of the fast-changing landscapes of capitalism, with its multiple links to everyone's lifestyles. Primarily directed at the corporate community, it has much to say about what scientists should bear in mind as they interact, whether wittingly or not, with the wider world. The book is not only an educational read, it is entertaining as well, thanks to its vigorous debates. Read it and ponder some of the implications of pursuing science at Earth, Inc.

Norman Myers is at Upper Meadow, Old Road,

Headington, Oxford OX3 8SZ, UK. 